exalta con la autoridad de su vasta experiencia lo pasado sin desdeñar tampoco lo actual, y, de pie frente al porvenir, como figura profética, anuncia que la viril democracia, si evita antagonismos y mantiene libertades esenciales, ejercerá perpetua influencia espirituaí sobre los destinos de la América eviterna. -F R A N C I S C O G A R C í A C A L D E R ó N.

Exclusivo para Atenea en Chile.

\title{
LITERATURA Y ACTITUD AMERICANA
}

ब这个 UZGAR la obra, no a la manera habitual de los críticos literarios que la ponen siempre al servicio del esquema anticipado que suelen formarse de la Literatura, sino relacionándola con cierto tono vital que predomine en la época, buscando la correspondencia entre la forma y el contenido, puede ser una labor muy esclarecedora de experiencia crítica. Distinguiríamos así cierto estilo propio de cada generación, que descontando los elementos extremadamente individuale's, o aquello muy general de la técnica literaria, nos revelaría la actitud espiritual de una época ante el mundo, porque como quisiéramos comprobar, no es indiferente que en el dominio común de cada período literario prevalezcan con exclusión de otros ciertos adjetivos o epítetos; haya toda una estructura de metáforas, surjan expresiones con valor casi simbólico de signos para la inteligencia o la comunicación colectiva. Justamente en nuestra América, tierra todavía de colonización espiritual, y donde, por lo tanto, los pensadores originales son escasos, esta valoración de estilo y obra, nos ayudaría a fijar el perfil de cada generación, las ideas que asoman en el horizonte, la temperatura de la conciencia contemporánea. Comparar, por ejemplo, en nuestro pequeño mundo intelectual, una página de Rodó escritía hace quince años con una página reciente de Mariátegui, nos revelaría el camino recorrido en ese tiempo por la inteligencia y la sensibilidad americanas. No se trataría precisamente de analizar ideas: se nos objetará que Rodó es un plácido liberal y Mariátegui un revolucionario, pero hasta en aquel dominio que nos parezca menos contaminado por la pasión individual - un juicio artístico, una página de simple literaturafijaríamos las diferencias y las distancias. Cada época, cada generación viene a realizar sus propios problemas, a buscar en el mundo intereses nuevos, y cuando no lo hace y se contenta ron seguir bordando en el telar de la tradición, podemos hablar 
de estancamiento y decadencia. De aquí la importancia de la posición revolucionaria: todo gran pensador, todo gran artista, en cierto sentido es, necesita ser un revolucionario. Junto a él parecen simples "compagnons", artesanos decoradores, los que se conformaron gorda y muellemente en conservar la herencia adquirida y no arriesgaron una carta nueva. Como lo dijo Jesús y su glosador Kempis el camino del ideal es incompatible con cualquier otro camino. Y hay que elegir entre la tibia estufa burguesa y el descubierto cielo tempetuoso por donde el rey Lear se pasea con el flotante manto saeteado de relámpagos. El tiempo siempre hace justicia. Cada generación entierra a sus muertos, y la muerte y la sepultación, como el nacimiento y la vida, son una necesidad histórica.

El escollo de toda educación oficial es que no siempre reacciona ante estas leyes vitales de la cultura, ante el imperativo que arrastra cada época, y vacila entre el pasado y el porvenir, sin entregarse a ese rumbo que intuye, que olfatea más bien, el animal o el baqueano. Nuestros grandes hombres de América no fueron precisamente el producto de una pedagogía oficial y plantada fuera del tiempo, sino los que vieron con sus grandes ojos abiertos, olieron con sus narices cargadas de instinto y aprontaron sus manos para la realización de la hora que venía. En Bolívar y en Sarmiento hay que elogiar la fuerza del instinto; ese sexto sentido que palpa y perfora las tinieblas. Así la actual vida americana tiene en oposición a la actual vida europea un ritmo épico y germinante- de algo que se está haciendo-, que comunica a las nuevas generaciones, como contraste del "despaisamiento» y la alquitarada decadencia en que otras quisieran vivir, una voluntad de acción. Junto a esta exaltación de americanidad que se echa a andar, por ejemplo, en las firmes espaldas de un Diego Rivera, creador de mitos, forjador de una nueva fantasía revolucionaria, continúan bordoneando como insectos que se quemarán a la llama, los propulsadores de un arte sin realidad criolla que comen el alpiste manido de unas fórmulas de capilla europea, sin asidero en nosotros.

Pero lo que es posible ya afirmar siguiendo el ritmo de la hora histórica es que revolución (no una determinada revolución por un "ismo» determinado, ya que las circunstancias nacionales son diferentes), sino revolución en cuanto expresa cambio, firme despertar de las conciencias nacionales y actitud vigilante, y americanidad que enraíza en la tierra y se sumerge en la voluntad plástica del medio americano, serán dos rumbos indeclinables de la presente y la próxima hora continental. Al cosmopolitismo y la visión abstracta de nuestros escritores 
de hace veinticinco o treinta años, sucede hoy una visión concreta de la realidad americana. Antes nuestros escritores llegaban a lo americano de vuelta de lo europeo; partían del viejo mundo para justificar el nuevo, y España para los conservadores y puristas del tipo que fué frecuente en Colombia, y Francia para los radicales en Política y modernistas en Literatura, fueron arquetipos en que quisieron moldear su América. (Hubo también los exaltadores de lo anglosajón; y es curioso captar en el recio criollo que fué Sarmiento ese momento de duda cuando al salir de su visita a las escuelas de Concord y de Boston, piensa en Emerson y en Horacio Mann e idea un puritanismo sudamericano, una iglesia y una educación sin mitos para nuestras multitudes bronceadas. Naturalmente que el instinto de Sarmiento lo libraría después de esa ofuscación momentánea; prevaleció, por fin, el verdadero hombre que él era: todo instinto vital e iluminación fulgurante de la realidad criolla.) Hombres de más labrada prosa, pero de más débil personalidad: Rodó, García Calderón, estilizaron después su América al través de ornamentadas fórmulas europeizantes. Lo que en Sarmiento fué instinto, en ellos era fraseología. Más que para luchadores o apóstoles habían nacido para diplomáticos o para profesores de nuestras ampulosas universidades. Aunque intuyeran la verdad, no querían renunciar al adornado optimismo de su prosa. El culto de Rodó significó en un momento americano el gusto de las formas ornamentales y una ideología de tipo medio, muy honesta y poco peligrosa. En el año de 1910, el viejo hombre en quien aprendiera las virtudes del estilo y las leyes de la ironía demasiado intelectual, toda una generación de hombres criollos, Anatole France, llegaba a Sur-América al centenario argentino. Anatole France encarnó entonces para nuestros retóricos una cosa vaga y proclive a la declamación, que se llamaba la latinidad. En el memorable discurso de Montevideo, Rodó, que ya no era ese Rodó del juvenil retrato de las primeras ediciones de Ariel, sino un Rodó con gafas, ya gordo y cejijunto, saludaba al maestro francés como al sumo sacerdote de un espíritu y una tradición latina que también vivía en nosotros. Y en estas tierras de América veía Rodó dilatarse en ret6rica esa latinidad. No se le ocurría al profesor uruguayo otra fórmula americana que la que había aprendido en las suaves admoniciones de Renan y Guyau. Lo que el viejo France pensaba en ese momento de la latinidad de nuestros pueblos, su teatralidad de hombre que viene en misión de ceremonia, cerrado como buen francés a la comprensión de otros países, puede leerse en uno de los caústicos panfletos de Brousson. 
Según Brousson con su auxilio y el del Diccionario Enciclopédico y unos nombres de héroes criollos aprendidos durante la travesía, se improvisó el homenaje de France a la Argentina. Lo demás era alquimia de literato, secreto de frases y adjetivos y número de la prosa, que conocen muy bien los hombres del oficio. Pero en el mismo año o a comienzos del año siguiente, Francisco García Calderón bajo una de las carátulas rojas de Flammarion - tan decidoras para la gente de nuestra razapublicaba con prólogo de M. Poincaré sus Démocraties Latines de l'Amérique, libro que nos presentaba embellecidos e insistía también en esa reserva y prolongación de la culta Europa que nosotros constituíamos. Uno como individualismo dannunziano - a pesar de la Sociología-tornaba a su autor a ratos demasiado comprensivo y tolerante hasta de ciertas innegables estructuras bárbaras de nuestro medio americano, como esos caudillos azotes de sus pueblos, pero que en la formula de 1910 parecían individualidades jugosas, condotieros, productos de pueblos caóticos, pero ricos en posibilidades humanas. Así era un medio henchido de retórica modernista aquel de hace veinte años; tuvimos como nunca escritores alambicados y exquisitos, y la mayor aspiración de esos mansos estetas era colaborar en una bolnita revista gráfica que editaba en París Rubén Darío, o publicar sus libros en Ollendorf de París o Renacimiento de Madrid.

Ya penaban en el destierro en los últimos días del porfirismo varios mozos mejicanos. Y de la meseta mejicana, o del fondo de los valles donde los indios cultivan el maíz o la caña de azúcar del terrateniente, se fué elevando una conciencia revolucionaria que - dígase lo que se quiera-tuvo su expresión jurídica en la Constitución del año 17. 1917 y 1918, años de liquidaciones; el final de la guerra europea afirmó el balbucear de esa conciencia y la futura gran lucha contra el Imperialismo va dando a la nueva juventud hispanoamericana una fuerza de doctrina, un ímpetu colectivo que no conocieron otras generaciones.

El fenómeno se advierte en una serie de matices circunstanciales que, juzgados en función de la totalidad, aclaran el sentido de esta hora. Parte de esa juventud ya ni quiere llamarse hispanoamericana. En el deseo de acentuar su estrecha relación con la tierra, ha vuelto a lo indígena. El indio ya extinguido en algunos países o disuelto en medio de la población blanca, mestiza o mulata, representa el ensueño vernacular, la fórmula romántica de recobrar la tierra y la vuelta a esa hora dorada e irretornable en que la fiesta del Sol y las rap- 
sodias divinas que fluían de los labios de los Amautas, fueron interrumpidas por el galope frenético de la caballería invasora. Romanticismo sin duda, pero los pueblos en trance de crecer necesitan de la inspiración del mito. El romanticismo indigenista de Perú o de Méjico, descontando todo lo circunstancial y patético con que nos aparezca en la hora presente, es en todo caso una afirmación de cultura y nacionalidad, y guardando las proporciones, podría ser para esos pueblos un motivo de creación estimulante como para la Alemania afrancesada y pseudoclasicista del siglo XVIII, el redescubrimiento de lo g6tico. Por de pronto, ese repliegue sobre lo indio, ha permitido en los países aludidos la explicación de muchos aspectos de su psicología étnica y de formas de vida y de economía, sumergidas bajo el manto de una tradición europea, débilmente estratificada.

En la concatenación con el pasado que necesitan las naciones para continuar su ritmo histórico y que se llama la tradición, ahora nos interesan los hombres que ya intuyeran ese destino que dormía en sus pueblos, y contra el europeísmo y el elegante desarraigo de otras generaciones, irguieran-como una fuerza revolucionaria-su voluntad de «criolledad».

La relación con la tierra que pedíamos al escritor de América, está en el paralelo opuesto de la que puede tener el caudillo bárbaro. Este es la naturaleza en su flora primaria; aquel es precisamente el que viene a prender fuego al bosque virgen, para barbechar la civilización. Y hay un romántico encendimiento en esos hombres nuestros que tuvieron ímpetu y sacrificio suficientes para realizar èsá épica labor de rozadores o leñadores. Como las ideas no se injertaban entre nosotros como en los países de trabajada tradición en suelo propicio, tuvieron que alzar ese incendio de lianas o pastos secos con que el habitante de nuestras selvas o llanuras inicia en un verano muy seco su labor de siembra y sedentaridad. Una tormenta sigue a esos escasos hombres que reaccionaron contra su medio y buscaron un clima más puro: la tormenta de Bilbao en el Santiago de Chile pelucón y de achaparradas casas de 1850, la tormenta del ex-fraile Vigil en el adormecido Perú de mediados del siglo XIX, la voz de González Prada enderezándose como una conciencia sobre una república peruana, vencida y en bancarrota. Es esta actitud del intelectual opuesta a la indiferencia bobalicona, disfrazada de serenidad con que otros es- 
critores americanos vieron pasar la corriente turbia de nuestros problemas, la que nos conviene fijar como una ética y un derrotero para el escritor de América. Ella no quiere excluir la obra de arte, pero le pide a ésta, sin dejar de ser arte, más profundo arraigo en el medio. Aun desde el punto de vista estético, intenta superar la etapa de imitación externa que ha vivido el arte americano, por una creación más peculiar y propia. Nos interesa Diego Rivera no sólo porque es un pintor revolucionario (nomenclatura que pudiera estar fuera del arte), sino porque ha expresado con maestría una realidad revolucionaria que dormía en el alma de su pueblo. Así el artista crea o revela toda una nueva expresión de cultura. Y nuestra tradiciónporque es preciso tener alguna- enraíza más bien que con los retóricos tradicionales que sólo supieron conservar una forma ya estática y anquilosada, con los que abrieron el cauce para la circulación de nuevas verdades.

Recientemente el escritor peruano Luis Alberto Sánchez ha fijado en su Don Manuel, hermosísima biografía, la novela y la pasión de uno de esos precursores: González Prada. Interesa en el libro de Sánchez a más de su cabal realización literaria, la historia de la actitud que contiene. Porque es la actitud del hombre nuevo contra el hombre tradicional, del revolucionario contra el conservador. Hay quien pone sus ideas bajo la cerrada temperatura de un invernadero burgués, podándolas, moderándolas o aplicándolas según la oportunidad y la hora, y hay otro que quiere verlas germinar en los campos libres. El porvenir es del segundo. Porque las ideas, que también son producto humano, demandan como toda labor de hombre una descarga vital. Esto y no la opinión más o menos momentánea que bajo la impresión de su siglo, pudieron tener Sarmiento o González Prada sobre determinado problema local, es lo que importa como fuerza de tradición. En el libro a que antes nos referíamos, Luis Alberto Sánchez ha escrito la historia de una conciencia libre en un medio que no la comprendía; la subversión de un alma encendida contra la rutina, la ignorancia y el prejuicio, la tensa decisión de dignidad que lanza con la firmeza de un hondero contra su medio bárbaro, acomodaticio u hostil, uno de estos hombres. Cambian los problemas; en los carteles de la época-como en los avisos de los teatros-se escribe un nuevo programa, pero el fondo y el significado de la actitud permanecen idénticos.

Dan tales circunstancias a la labor del intelectual y a la inevitable lucha por las ideas en América, un carácter épico y un encendimiento romántico, que es el dolor, pero que es tam- 
bién la belleza de la actitud. En estas historias-la de Sarmiento contada en prosa pindárica por Lugones; la de González Prada escrita con más fino don de intimidad por Luis Alberto Sánchez-se ve siempre la apostura de un titán luchando contra los geniecillos peludos y venenosos de su medio vernáculo. A veces-como en uno de los más conmovedores capítulos escritos por Luis Alberto Sánchez-, cae sobre el luchador una obscura hora de soledad en que solo le restan la sonrisa y comprensión de sacrificio de una mujer. Pero cuando el caudillo, uno de estos caudillos que en nuestra historia americana se cruzan en el camino del intelectual y están acostumbrados a hacerle su amanuense, panegirista o sofista de ocasión y remacharle por tanto, una cadena de servidumbre, quiere como el caudillo Piérola sobre González Prada, lograr su renunciamiento, el intelectual yergue en desesperado combate contra las cosas, toda la dimensión de su entereza. Historias edificantes de ayer, de todos los días, que nos placen más que ese vano y retorcido juego de caligramas en que otros escritores de América dejaron escaparse su hora.- M A R I N O P I C ó N S A L A S.

\section{GRÓNICA DE ESPEGTẢGULOS}

\section{El Teatro Real.-Berta Singerman}

TUENIO d'Ors decía, hace algunos años, a los muchachos He la Residencia de Estudiantes:

Belleza no quiere decir ornamento, sino armonía, 'adecuación delicada de la cosa a su destino.

A un tiempo, en Francia, otra voz concordaba con la del filósofo de Cataluña; Le Corbusier formulaba su famoso principio estético:

Una casa es una máquina para vivir.

En ambas afirmaciones, que componen un solo postulado, descansa el principio de actualidad en las artes, que no equivale a una antojadiza orientación del deseo de originalidad, sino que traduce la idiosincrasia de una época.

El practicismo, las necesidades del confort y las tendencias deportivas de las costumbres modernas han creado un estado de ánimo incompatible con el barroquismo. La vida ha adquirido hoy día cierta allure que repudia la inocuidad del arabesco.

Por lo que se refiere a la arquitectura, los nuevos materiales 